\title{
APROXIMACIÓN A LAS COSTUMBRES LITÚRGICAS Y USOS DEVOCIONALES DE LAS CAPILLAS, ERMITAS Y ORATORIOS DE JEREZ DE LA FRONTERA
}

\author{
PABLO J. POMAR RODIL | UNIVERSIDAD DE CÁDIZ
}

ORCID iD: 0000-0002-0918-1739

\section{RESUMEN}

Jerez de la Frontera contó, además de con sus parroquias y conventos, con una tupida red de edificios de culto secundarios, de menor entidad arquitectónica, que coadyuvó en la sacralización de la ciudad y su término. Estas pequeñas iglesias -principalmente ermitas, capillas, oratorios- facilitaban a la población el acceso a determinados sacramentos, al tiempo que servían de lugar de veneración de algunas de las imágenes históricas de mayor devoción para los jerezanos.

\section{PALABRAS CLAVE}

Liturgia, devoción, capillas, ermitas, oratorios, Jerez de la Frontera.

\section{AN APPROACH TO THE LITURGICAL CUSTOMS AND DEVOTIONAL USES OF THE CHAPELS, HERMITAGES AND ORATORIES OF JEREZ DE LA FRONTERA}

\begin{abstract}
In addition to its parishes and convents, Jerez de la Frontera also had a dense network of secondary buildings of worship, of lesser architectural importance, which contributed to the sacralisation of the city and its environs. These small churches - mainly hermitages, chapels and oratories - provided the population with access to certain sacraments, while at the same time serving as places of veneration for some of the historical images of greatest devotion for the people of Jerez.
\end{abstract}

\section{KEYWORDS}

Liturgy, devotion, chapels, hermitages, oratories, Jerez de la Frontera. 
J

erez de la Frontera estabilizó su estructura eclesiástica secular en el siglo XV, cuando pasó de las seis parroquias fundacionales, entre ellas la colegiata de San Salvador, a ocho, al sumar las nuevas fundaciones de los arrabales, Santiago y San Miguel ${ }^{1}$. A esta red primaria que garantizaba la atención sacramental de la población, hay que añadir la que conformaban las fundaciones religiosas, que con sus diversos carismas coadyuvaron en el proceso de concepción ciudadana como pequeña cristiandad, y que no cesaron de aumentar, desde la baja Edad Media y durante toda la Edad Moderna, hasta alcanzar el crecido número de quince conventos masculinos y nueve femeninos ${ }^{2}$. Además de los hospitales, con su propia historia marcada por la reducción de 1587, cosida a la urdimbre de este sacralizado tejido urbano y aún de su alfoz, una trama de ermitas, capillas y oratorios permitía intensificar la presencia de lo religioso en la vida de los jerezanos ${ }^{3}$. La historia arquitectónica y artística de estas pequeñas iglesias ha sido objeto de algunos estudios que han permitido conocer -en unos casos con mayor concreción que en otrosdataciones, implicaciones artísticas y patronazgos, estudios que se integran en el presente trabajo con nuevas informaciones documentales y con la relectura de otras, a las que no se había atendido suficientemente, de cara a completar el conocimiento de estos templos menores en función de su uso devocional y funcionalidad litúrgica ${ }^{4}$.

Sujetos al ordinario como las parroquias, estos pequeños templos diseminados por la ciudad, con mayor incidencia en su extramuros, y también en sus alrededores y sus campos, habían sido erigidos generalmente por iniciativa de los fieles o de algún gremio o cofradía, pero igualmente los hubo de patronazgo real o municipal. En algunos de ellos incluso se fundaron capellanías y con frecuencia servían al pueblo para cumplir con el precepto dominical y dar culto a algunas imágenes de devoción. Además, son frecuentes las noticias referentes a los rosarios que diariamente se rezaban en estas pequeñas iglesias, también a

1 JimÉnez LÓPEZ DE EGUILETA, J. E. y POMAR RODIL, P. J. 2014, Domus Dei et Porta Coeli. Jerez, entre parroquias y conventos. En JIMÉNEZ LÓPEZ DE EGUILETA, J. E. y POMAR RODIL, P. J. (Eds.) Limes Fidei. 750 años de Cristianismo en Jerez. Jerez de la Frontera: Diócesis de Asidonia-Jerez. pp. 226-227.

2 Idem.

3 PÉREZ GONZÁLEZ, S. M. 2014, Cofradías y hospitales del Jerez de finales de la Edad Media (1392-1504). En JIMÉNEZ LÓPEZ DE EGUILETA, J. E. y POMAR RODIL, P. J. (Eds.) Limes Fidei. 750 años de Cristianismo en Jerez. Jerez de la Frontera: Diócesis de Asidonia-Jerez. pp. 128-144.

4 Las principales aportaciones documentales del presente trabajo proceden del Archivo del Arzobispado de Sevilla (en adelante AGAS), donde se conservan asentadas las resultas que los visitadores dejaban a disposición del provisor y, en última instancia, del propio arzobispo, tras girar visita a cada parroquia de la archidiócesis. Suponen una fuente de información de primer orden para reconstruir la historia de los templos parroquiales, pero, como en este caso, también de las capillas, ermitas y oratorios que, sujetos al ordinario, existían en el territorio de cada una de las parroquias visitadas. 
las novenas, sermones y otras funciones que tenían lugar en ellas. Así consta cómo en 1673 se rezaba el rosario todas las noches en la capilla de Las Angustias ${ }^{5}$, de lo que vuelve a haber constancia en 1715, igualmente de noche, a prima, en La Caridad y en Los Remedios ${ }^{6}$. Con frecuencia de cotidianidad estos actos piadosos incluso desbordaban los propios recintos para sacralizar el callejero con rosarios de la aurora o nocturnos, de los que encontramos noticia, por ejemplo, en 1725, cuando la procesión del rosario salía "por las calles a dicha ora [de prima] de la hermita de nuestra señora de las Angustias, de la de los Desamparados y la de San Telmo, a solicitud de la devoción de las hermandades citas en dichas hermitas" 7 . Por último, los oratorios privados supondrían la penetración de este espíritu de piedad en el interior de las propias casas y palacios de la nobleza local, que separaban cuartos en sus moradas para acondicionarlos como delicadas iglesias domésticas, templos en miniatura en los que, con las debidas bulas y licencias, se permitía incluso la celebración del sacrificio de la misa ${ }^{8}$.

\section{Figura 1}

Real capilla de Santa María del Alcázar

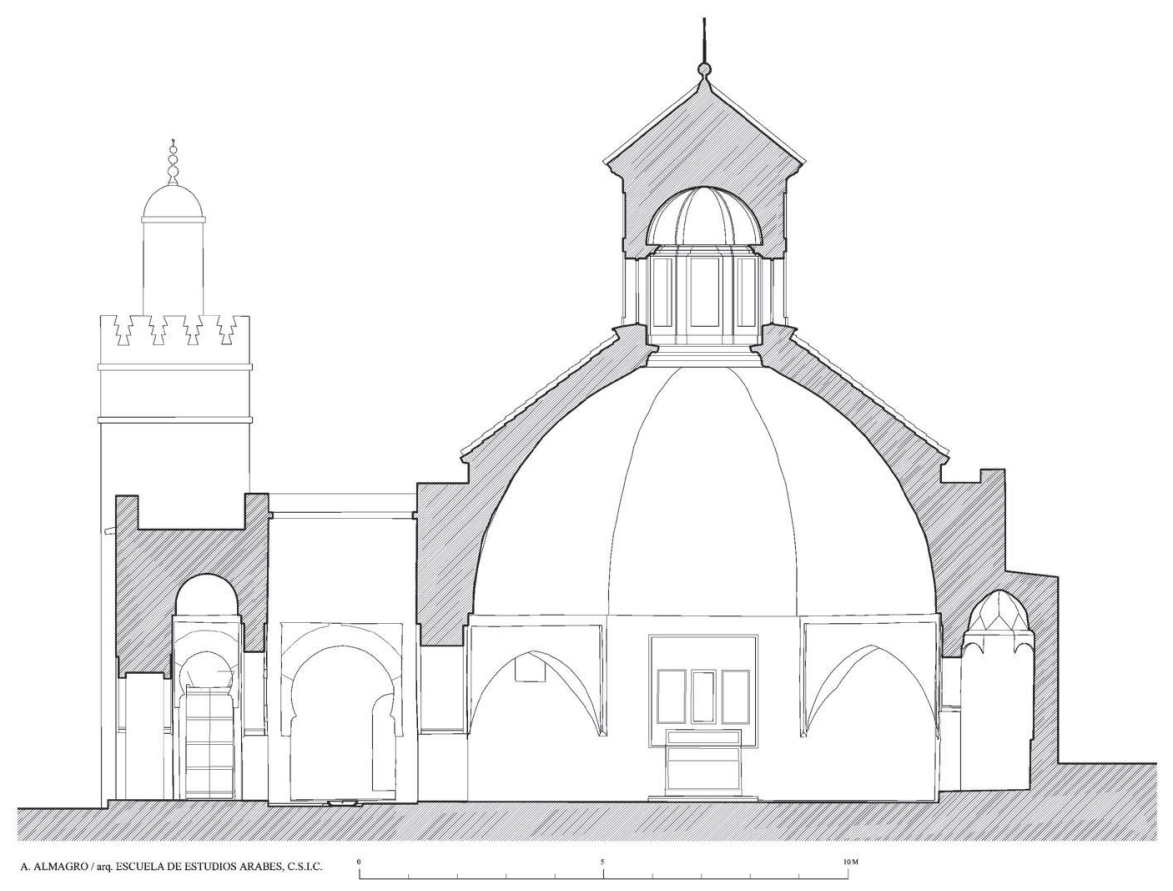

5 AGAS. Sección II, visitas, legajo 1443, s./f.

6 AGAS. Sección II, visitas, legajo 1359, f. 159 r.

7 AGAS. Sección II, visitas, legajo 1367, f. 70 r.

8 Existe en el Archivo del Arzobispado de Sevilla abundante documentación sobre estas bulas y licencias para los oratorios del Jerez de los siglos XVI al XVIII. AGAS, sección II, serie 9, legajos 14-A y 14-B. 


\section{LA REAL CAPILLA DE SANTA MARÍA DEL ALCÁZAR}

El origen de algunas de las capillas de la ciudad se remonta a los años inmediatamente posteriores a la Reconquista 9 . Entre estas destaca la de Santa María, que había sido fundada por el rey Alfonso X en la que fuera en época almohade mezquita palatina del Alcázar (Figura 1$)^{10}$. El Rey Sabio la dotó para que se celebrase misa en ella cada primer sábado de mes, el día de San Ildefonso, el de San Nicolás y otros aniversarios fijados por el alma de reyes de Castilla ${ }^{11}$. De ello quedaron encargados los llamados clérigos de Santa María del Alcázar, una suerte de capellanes reales que en 1283 desaparecieron como tales al extenderse la obligación a todos los canónigos y beneficiados de la ciudad, que a partir de entonces debieron asistir coralmente a ciertas misas señaladas que habrían de celebrarse de manera solemne, esto es, cantadas y con el auxilio de diácono y subdiácono ${ }^{12}$. Con posterioridad, el culto se fue enriqueciendo con nuevos oficios y misas de sufragio, si bien en la Edad Moderna pasó igualmente por períodos de decadencia, que repercutieron en detrimento de su decoro material. Al respecto cabe señalar la desoladora descripción que hizo en 1716 el visitador don Pedro Fernández de Zurita: “en lo material tan ynmunda e yndezente y tan descompuesta que ni aun puertas tiene y solo la defienden unas mui viexas en el pórtico entre el qual y el cuerpo de dicha capilla media un patinillo adonde sale la puerta de dicha capilla sin puertas de madera ni defensa alguna" ${ }^{13}$. Fernández de Zurita creyó encontrar la raíz del problema en las condiciones del privilegio que regulaba los aniversarios de esta Real Capilla, que había sido otorgado por los Reyes Católicos a los canónigos y a la universidad de beneficiados de Jerez en $1495^{14}$. Éste establecía que, si bien el adorno de su altar era obligación de la fábrica de la Colegial, sus reparos lo eran del alcaide, por lo que solicitó para su remedio la intervención del cardenal arzobispo de Sevilla, don Manuel Arias y Porres $^{15}$. A pesar de ello, no sería hasta diez años más tarde cuando se levantaría un nuevo

9 JIMÉNEZ LÓPEZ DE EGUILETA, J. E., 2016. Devociones marianas en Jerez y su comarca durante los primeros tiempos de la conquista cristiana. En Asidonense. no. 10, pp. 55-83.

10 Ibidem, PP. 56-58.

11 MESA GINETE, F. de, 1888. Historia Sagrada $\gamma$ Política de la Mup Noble $\gamma$ Mup Leal Ciudad de Tarteso, Turdeto, Asta Regia, Asido Cesariana, Asidonia, Gera, Jerez Sidonia, hov Jerez de la Frontera. Jerez de la Frontera: Melchor García Ruiz. t. I, PP. 187-188.

12 JIMÉNEZ LÓPEZ DE EGUILETA, J. E., 2014, Privilegio rodado de Enrique III al clero de Jerez (1393). En JIMÉNEZ LÓPEZ DE EGUILETA, J. E. y POMAR RODIL, P. J. (Eds.) Limes Fidei. 750 años de Cristianismo en Jerez. Jerez de la Frontera: Diócesis de Asidonia-Jerez. pp. 314-315.

13 AGAS. Sección II, visitas, legajo 1454, s/f.

14 Idem.

15 Idem. 
retablo mayor, que ejecutó el poco conocido retablista Alonso Barrero ${ }^{16}$. Así, con ciertos altibajos, se mantuvo hasta mediados del siglo XIX, cuando los cambios introducidos por el nuevo concordato de Isabel II dieron al traste con esta memoria viva de la Reconquista cristiana, iniciándose para el edificio un lento proceso de desacralización que cristalizaría con su musealización ya en el siglo $\mathrm{XX}^{17}$.

\section{CAPILLAS DEVOCIONALES, HOSPITALARIAS Y DE COFRADÍAS}

La intervención de los santos durante la Reconquista cristiana no sólo marcó la dedicación de una de las parroquias a San Dionisio, sino que propició la aparición de capillas en su alfoz, que conmemoraban la decisiva intercesión de ciertos santos que, según la tradición, hicieron posible la victoria castellana para la reposición de la fe católica en España y, más concretamente, en Jerez ${ }^{18}$. De esta época de guerra y frontera serían también las ermitas de San Miguel y Santiago, germen de las parroquias homónimas ${ }^{19}$, y la de Nuestra Señora de los Remedios, que inicialmente no fue más que un altar en un hueco abierto en la muralla junto a la Puerta Real. Allí se veneraba una imagen de la Virgen que, según la tradición, habría auxiliado a los caballeros en la batalla de los Cueros y que, por su devoción, llegó a contar con una cofradía cuyas reglas se aprobaron en $1517^{20}$. Poco después, entre 1524 y 1534, la mencionada cofradía levantaría, frente al primitivo altar callejero, una verdadera capilla con capacidad para cuatro altares además del mayor ${ }^{21}$. La propia naturaleza de estos pequeños templos devocionales, pobremente dotados y con escaso solar disponible de origen, redundaba en una endémica falta de espacio para los fieles cuando la hermandad crecía en miembros. En esta de los Remedios (Figura 2) la capacidad de acoger a cofrades y devotos fue quedando pequeña a medida que éstos au-

16 ANTÓN PORTILLO, J. y JÁCOME GONZÁLEZ, J., 2001. Apuntes histórico-artísticos de Jerez de la Frontera en los siglos XVI-XVIII (2 ${ }^{\mathrm{a}}$ serie). En Revista de Historia de Jerez. no. 7, p. 110.

17 REPETTO BETES, J. L., 1986. Historia del Cabildo Colegial de Jerez de la Frontera. 1264-1984. Jerez de la Frontera: Caja de Ahorros de Jerez. pP. 51-52.

18 JIMÉNEZ LÓPEZ DE EGUILETA, J. E. y POMAR RODIL, P. J. 2014, La conquista de Jerez y la intercesión de los santos. En JIMÉNEZ LÓPEZ DE EGUILETA, J. E. y POMAR RODIL, P. J. (Eds.) Limes Fidei. 750 años de Cristianismo en Jerez. Jerez de la Frontera: Diócesis de Asidonia-Jerez. pp. 188-189.

19 Sobre el proceso de conversión de ambas ermitas en parroquias se desconoce casi todo. Arroja algo de luz JIMÉNEZ LÓPEZ DE EGUILETA, J. E. 2014, La Iglesia en Jerez durante el siglo XIV. En JIMÉNEZ LÓPEZ DE EGUILETA, J. E. y POMAR RODIL, P. J. (Eds.) Limes Fidei. 750 años de Cristianismo en Jerez. Jerez de la Frontera: Diócesis de Asidonia-Jerez. PP. 104-105.

20 MESA GINETE, F. de, 1888, t. II, P. 234.

21 SERRANO PINTEÑO, J., 2000. El primitivo retablo de la capilla de Nuestra Señora de los Remedios. En Revista de Historia de Jerez. no. 6, PP. 175-181; MARISCAL RODRÍGUEZ, M. Á. y POMAR RODIL, P. J., 2004. Jerez. Guía artística $\gamma$ monumental. Madrid: Sílex. p. 113; AGAS. Sección II. Serie visitas, legajos 1443, s./f.; 1348, ff. 24r.-28r.; 1385, s./f. 
mentaban durante el siglo XVII, y no sólo eso, sus cuatro gruesos pilares les suponían un inconveniente visual importante a la hora de seguir las misas que se celebraban en algunos de sus cinco altares. La imposibilidad de ampliar el templo llevó en 1688 a los hermanos mayores de la cofradía, Alonso de Rueda y Baltasar López de la Cerda, a pedir auxilio económico al Cabildo Municipal para acometer la sustitución de los mencionados pilares por columnas clásicas, al disminuir la menor sección de éstas el inconveniente visual que aquellos representaban ${ }^{22}$.

Figura 2

\section{Capilla de Ntra. Sra. de los Remedios}

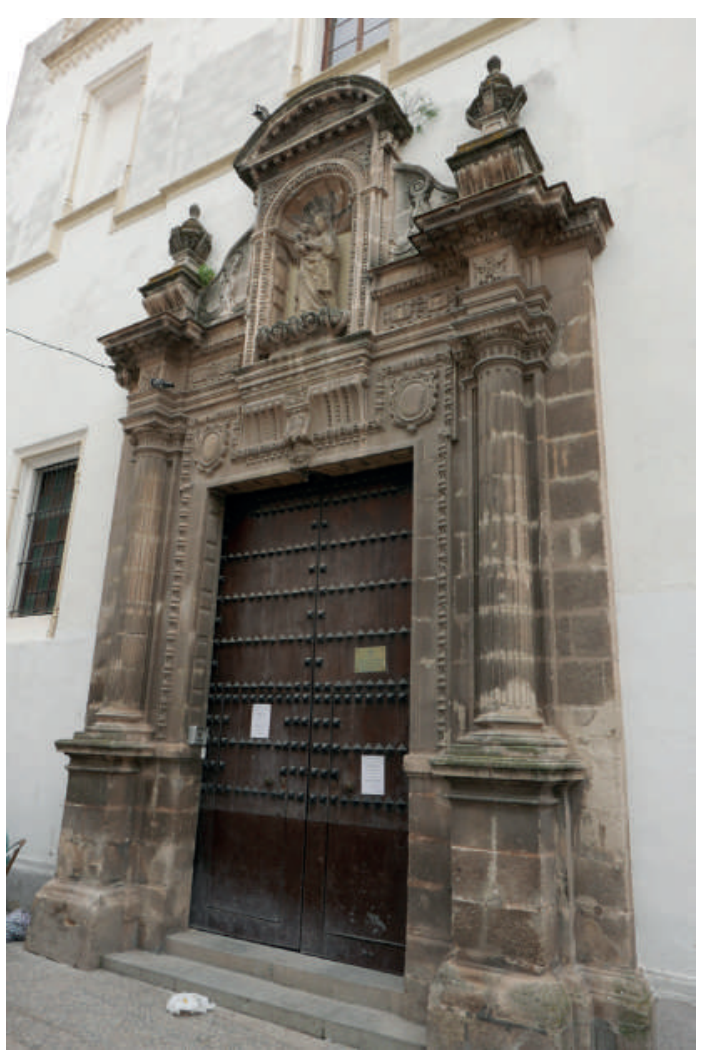

De génesis eminentemente vinculada a cofradías gremiales y penitenciales serán las ermitas de San Telmo, Las Angustias y El Calvario, todas del siglo XVI. La primera de ellas, fundada por el gremio de barqueros en los confines del arrabal de San Miguel, tuvo su

22 RÍOS MARTíNEZ, E. de los, 2003. Antón Martín Calafate y Diego Moreno Meléndez en la Arquitectura Jerezana del Siglo XVII. Sevilla: Universidad de Sevilla. p. 143. 
origen en $1575^{23}$. De su inicial vida litúrgica y devocional sabemos poco, apenas que contaba con tres altares y que se celebraba misa los días de fiesta, de lo que informa la resulta de visita de 1673 a la que tantas veces nos hemos referido ${ }^{24}$. Ya a finales del siglo XVI se había fundado en la ermita la Hermandad del Cristo de la Expiración, lo que propició su ampliación durante la centuria siguiente -principalmente a costa de la incorporación de calles colindantes- para "que se agrande la yglesia para que acudan hermanos y sea en aumento de su santo servicio", como se menciona en 1628, y también sucesivamente a lo largo de aquel siglo y aún del siguiente ${ }^{25}$. De hecho, el púlpito del siglo XVIII, que se conserva, y la petición de la hermandad al Ayuntamiento en 1764 de poder sembrar olivos en las inmediaciones para tener aceite para la lámpara de la Virgen del Valle, cotitular de la cofradía, ponen de manifiesto el mayor esplendor del culto y la devoción a sus imágenes alcanzado en ese siglo 26 .

\section{Figura 3}

\section{Ermita del Calvario}

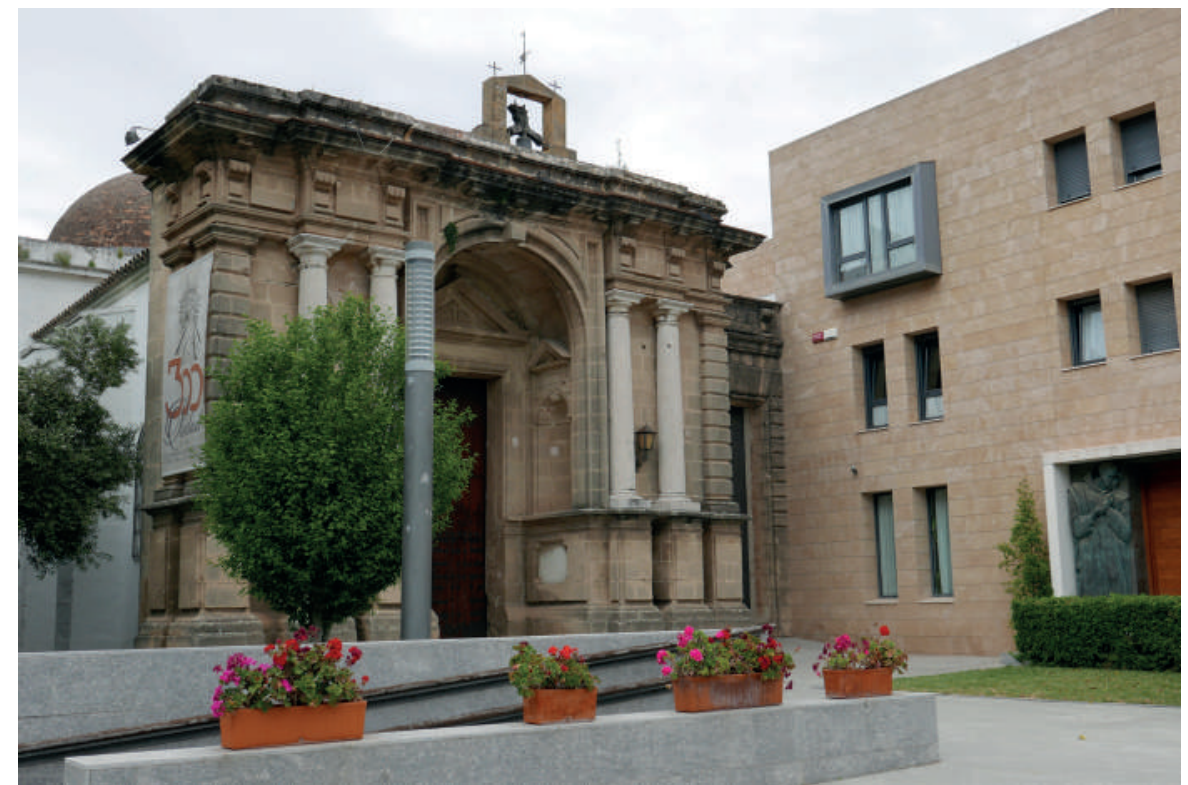

23 MARISCAL RODRÍGUEZ, M. Á. y POMAR RODIL, P. J., 2004. p. 206

24 "En un barrio que llaman San Telmo otra capilla ermita de este nombre donde hay una cofradía y los hermanos cuidan de su limpieza y la gente del son muy pobres y en ella se les dice misa los días de fiesta", AGAS. Sección II, visitas, legajos 1443, s./f.

25 AROCA VICENTI, F., 2018. El Jerez de Ignacio López. Apuntes sobre una ciudad sacralizada. En MORENO ARANA, J. M. (Ed.): El escultor Ignacio López y su época (1658-1718). Jerez de la Frontera: Libros Canto y Cuento, P. 122, n. 130.

26 Ibidem, p. 123 n. 134. 
Fue habitual en muchas poblaciones que en una zona elevada de las afueras se edificase un trasunto del monte Calvario, tratando de quedar así convertidas en una suerte de vernácula Jerusalén. Parece que ya en 1420 existía en la ciudad de Jerez un humilladero con estas características, si bien las noticias que lo habrían de atestiguar son de cierta fragilidad ${ }^{27}$. Desde luego conocemos el dato de que en 1567 Digo Ximenez Marocho dejó una renta "para que se haga una capilla de buena obra en el mismo sitio donde estaba la cruz que se decía del Monte Calvario para humilladero" ${ }^{28}$. No sabemos si la ermita llegó o no a construirse, pues en 1629 se habla de nuevo del inicio de unas obras "en el Monte Calvario" para capilla del Santo Entierro de Cristo, donde los fieles podrían lucrar las indulgencias que su hermandad tenía concedidas ${ }^{29}$. La configuración del espacio en relación con los santos lugares jerosolimitanos sigue estando presente hasta el punto de edificarse, precisamente en aquellos años y en la mencionada capilla, una Scala Santa, también rica en indulgencias, a semejanza de aquella por la que Cristo subió hasta el pretorio de Poncio Pilato y que, desde 1589, contaba en Roma con un nuevo edificio en el Laterano ${ }^{30}$. Una sucesión de obras llevadas a cabo durante el siglo XVII terminaría por convertir el viejo humilladero medieval en el edificio que actualmente se conserva ${ }^{31}$ (Figura 3). Éste debió de estar ya concluido, a falta del camarín que se le añadiría avanzado el siglo XVIII, cuando en 1705 alcanzó a conocerlo el visitador don Juan Bejarano Muñoz, quien lo describió del siguiente modo: "ay en esta parrochia de San Tiago una hermita o capilla que llaman del Calvario cuya yglesia es toda de cantería mui primorosa y bastante capaz, con tres altares mui bien adornados y con todo lo necesario para la celebrazión del Santo Sacrificio de la missa. Aquí esta cita una hermandad que llaman del Santo Entierro que es de gran copia de hermanos y lo son primeros cavalleros desta ciudad; y en el altar mayor está una ymagen de Jesuchristo en un sepulcro adornado con mucha plata y gran primor y aseo. Es este simulacro la más atenta deboción de los de los vezinos desta ciudad"32.

También sobre un humilladero preexistente sería levantada en el siglo XVI la capilla de la virgen de las Angustias, que contaba con cañón para el entierro de los hermanos ${ }^{33}$. Las re-

27 MARISCAL RODRÍGUEZ, M. Á. y POMAR RODIL, P. J., 2004. PP. 167-168.

28 MUÑOZ Y GÓMEZ, A., 1903. Noticia histórica de las calles $\gamma$ plazas de Xerez de la Frontera. Sus nombres $\gamma$ orígenes. Jerez de la Frontera: Imprenta de El Guadalete. p. 217.

29 RÍOS MARTÍNEZ, E. de los, 2003. pp. 145-147.

30 Idem.

31 Idem.

32 AGAS. Sección II. Serie visitas, legajo 1348, s./f.

33 MARISCAL RODRÍGUEZ, M. Á. y POMAR RODIL, P. J., 2004, PP. 184-185. 
glas de 1631 supusieron la confirmación de la devoción a esa imagen de la piedad y en 1673 solicitaron a la Ciudad que se le concediese un espacio para su ampliación, lo que repiten en 1678, justificando la necesidad de ampliar el templo un cuerpo más en el aumento de hermanos y devotos que acudían a la capilla a rezar el rosario de la Aurora ${ }^{34}$. La definitiva ampliación del siglo XVIII, que suponía la sustitución del viejo templo por uno nuevo que no se llegó a concluir, pone de manifiesto la pujanza vivida por la cofradía en aquella centuria y que tendría como culminación arquitectónica y pictórica la obra del nuevo camarín que habría de albergar la imagen titular ${ }^{35}$.

Otras capillas habrían tenido un origen hospitalario y asistencial, como las de la Caridad, los Desamparados o la de la Sangre. La capilla de Nuestra Señora del Refugio de los Desamparados, erigida por la Hermandad de la Misericordia en 1690, fue patronato de la familia Villacreces, que ostentó su titularidad hasta el siglo XX, cuando quedó convertida en sede de una cofradía de penitencia ${ }^{36}$. Poco después, en 1696, cuando la hermandad se trasladó a la calle Jubeteros, se dió el tentativo frustrado de que fuese utilizada como ayuda de parroquia de San Miguel $^{37}$. En la nueva ubicación sería conocida bajo el nombre de la Santa Caridad y estaría a cargo de la nobleza de la ciudad. Sabemos por el visitador don Juan Bejarano Muñoz que en 1705 su templo contaba con tres altares “decentes y bien adornados y con todo lo necesario para celebrar en ellos y en el mayor ay sacramento" ${ }^{38}$. Igualmente también da la noticia de que contaba con una taca donde se conservaban los óleos que se habrían de administrar cuando por el repentino empeoramiento de uno de los enfermos "no se puede aguardar venga de la parrochia [de San Dionisio]"39 ${ }^{39}$ El hospital de la Sangre, fundado en 1485 , tenía su capilla dedicada a la Resurrección de Cristo ${ }^{40}$. Tras una azarosa historia, con reducciones y cambios de usos, la iglesia fue levantada de nuevo en el siglo XVIII ${ }^{41}$. Incrustada en su portada ba-

34 RÍOS MARTÍNEZ, E. de los, 2003. pP. 279-280.

35 AGUILAR MOYA, L., MARTÍN MOCHALES, C., MORILLO PÉREZ, M. P., 2007. La restauración de las pinturas murales del Camarín de la Virgen de las Angustias de Jerez de la Frontera. Jerez de la Frontera: Ayuntamiento de Jerez de la Frontera, p. $9-13 ; 57-60$.

36 CASTRO MORENO, G., 2000. La capilla de Ntra. Sra. del Refugio de los Desamparados, herencia de la cofradía de la Santa Caridad. En Revista de Historia de Jerez. no. 6, pp. 129-138.

37 AROCA VICENTI, F., 2018, p. 124.

38 AGAS. Sección II. Serie visitas, legajo 1348, s./f.

39 AGAS. Sección II. Serie visitas, legajo 1348, ff. 24r-28r.

40 SERRANO PINTEÑO, J., 2014. El Hospital de la Sangre. De la fundación a la reducción de 1636. Nuevos datos. En Revista de Historia de Jerez. no. 16-17, pp. 99-13.

41 SERRANO PINTEÑO, J., 2004. Reformas barrocas en el Hospital de la Sangre de Jerez de la Frontera: Juan Díaz de la Guerra y Rodrigo de Alva. En Revista de Historia de Jerez. no. 10, pp. 105-112. 
rroca aún se conserva el alabastro de Nottingham - ahora una réplica del mismo-con la escena de la Resurrección, que fue mencionado por el pintor Francisco Pacheco en su Arte de la pintura ${ }^{42}$.

Figura 4

\section{Capilla de San Juan de Letrán}

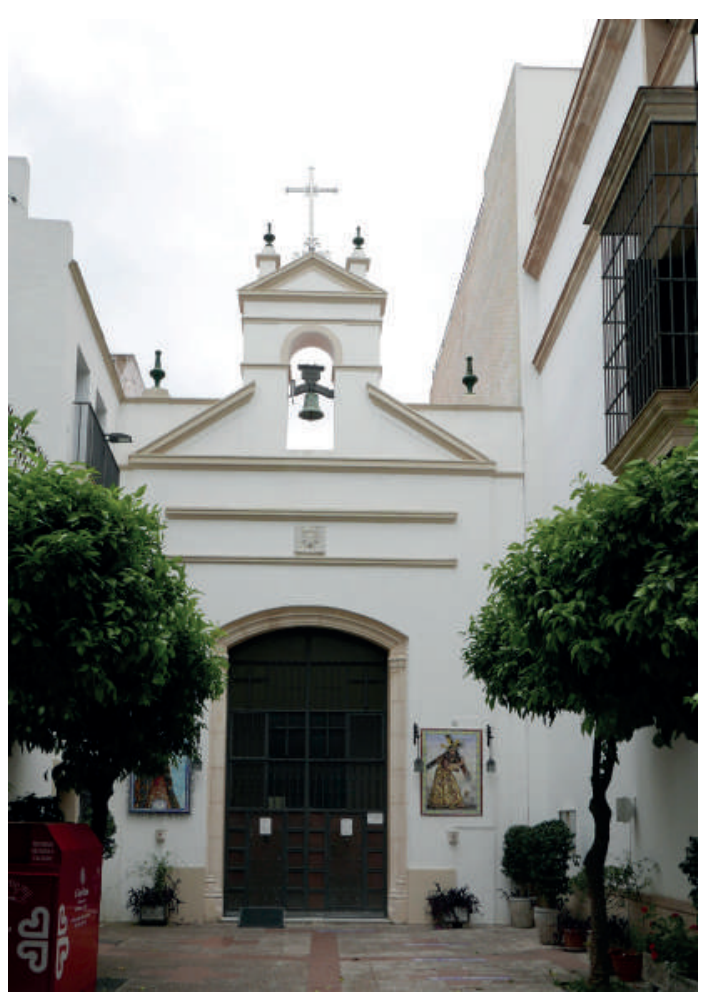

\section{LAS CUASIPARROQUIAS DE SAN ILDEFONSO Y SAN JUAN DE LETRÁN}

Una pequeña iglesia de la collación de San Mateo sobre cuya fundación se asienta una densa nebulosa que complica el conocimiento de su historia inicial es la de San Ildefonso. Consta su existencia ya en el siglo XIV, pero a mediados del siglo XVI adquiere una renovada importancia al ser dotada por la familia Dávila, que la tomó como enterramiento de su linaje y que, según ciertas fuentes, habría obtenido incluso el privilegio de pila bautismal para los miembros de su familia, lo que la habría convertido en una suerte de insólita parroquia pa-

42 "Esto del Sepulcro abierto y Cristo sacando una pierna de él para salir lo he visto muchas veces pintado, y en Xerez de la Frontera en la puerta del Convento de las Recogidas está esculpida en piedra" PACHECO, F., 1649. Arte de la pintura. Su antigüedad y grandezas. Sevilla: Simón Faxardo. p. 542. 
latina con la que los Dávila habrían pretendido reafirmar la singularidad e importancia de su linaje en el contexto nobiliario jerezano ${ }^{43}$. El acusado deterioro de la capilla hacia 1614 obligó a mudar sus capellanías a San Mateo y a la colegiata, al tiempo que propició la dispersión de su mobiliario, ajuar e imágenes, entre las que cabe destacar la Virgen del Socorro, que los Dávila entregarían a los agustinos, que en aquellos años se encontraban reconstruyendo el convento de Nuestra Señora de Guía ${ }^{44}$. Sin embargo, la capilla de San Ildefonso no desapareció de inmediato, al contrario, en situación ruinosa y sin culto alguno continuó existiendo hasta su sustitución por un casco bodeguero en la segunda mitad del siglo XIX ${ }^{45}$.

La que indudablemente sí dispondría de pila propia sería la capilla de San Juan de Letrán (Figura 4), si bien por motivos diametralmente opuestos a los exclusivos que parecían estar en el origen de la de San Ildefonso. Sin ser parroquia, al carecer de collación propia, esta capilla servía de ayuda de parroquia a las iglesias de San Miguel y Santiago, y en cierto modo también a las demás. Su origen está íntimamente ligado al hospital de San Sebastián, que estaba situado extramuros, frente al convento de Santo Domingo, ya que fueron los hermanos de la cofradía hospitalaria quienes en 1488 donaron al cabildo catedral de San Juan de Letrán de Roma un trozo de terreno colindante al hospital para levantar en él una iglesia agregada a la mencionada basílica lateranense ${ }^{46}$. La bendición del templo tuvo lugar en 1508, cuando habría sido concluída su cabecera gótica ${ }^{47}$. En 1517, el cabildo romano facultó a los hermanos para que erigiesen en la iglesia un cabildo exento del ordinario con deán, arcipreste, doce canónigos y seis prebendados ${ }^{48}$. Sin embargo, las condiciones para su dotación y el hecho de que ésta tuviese que ser renovada por quinquenios impidieron su aplicación ${ }^{49}$. Finalmente, el arzobispo de Sevilla concedió a la iglesia sagrario y pila de bautismo, así como

43 ROJAS VACA, M. D., 1998. Un registro notarial de Jerez de la Frontera: (Lope Martínez, 1392). Madrid: Fundación Matritense del Notariado. p. 199; MESA GINETE, F. 1888, t. I, p. 182.

44 También en 1619 la campana fue prestada por don García y don Bartolomé Dávila, patronos de San Ildefonso, al convento de Santo Domingo. MESA GINETE, F. 1888, t. I, PP. 179 y 182.

45 Contrariamente a cuanto sostiene Esperanza de los Ríos, la capilla de San Ildefonso no sirvió de parroquia provisional a la de San Mateo cuando ésta sucumbió al terremoto de Lisboa de 1755. MUÑOZ Y GÓMEZ, A., 1903. PP. 150-151; ÁLVAREZ LUNA, M. Á. et alii, 2018. La iglesia de San Ildefonso. En JIMÉNEZ LÓPEZ DE EGUILETA, J. E. (Ed.) La parroquia de San Mateo de Jerez de la Frontera: historia, arte y arquitectura. Murcia: Universidad de Murcia. p. 155; RÍOS MARTÍNEZ, E. de los, 2003. p. 21.

46 ROMERO BEJARANO, M., 2014. Del mudéjar al gótico. Arquitectura religiosa a finales del XV en Jerez. En ": BAREA RODRÍGUEZ, M. A. y ROMERO BEJARANO, M. (Eds.): Actas del Congreso Científico Conmemorativo del 750 Aniversario de la Incorporación de Jerez a la Corona de Castilla: 1264-2014. Jerez de la Frontera: Ayuntamiento de Jerez de la Frontera, p. 454.

47 MESA GINETE, F. de, 1888. t. II, p. 323.

48 Idem.

49 Ibidem, t. II, p. 324. 
sacristán y cura. Éste tendría que celebrar misa y renovar las formas del sagrario, así como confesar y administrar el bautismo a los recién nacidos de familias pobres que pidiesen dicho sacramento ${ }^{50}$. Su funcionamiento cuasiparroquial determinó que contase incluso con cementerio propio, de lo cual hay noticia ya en $1575^{51}$. La continuidad de la capilla en los términos descritos está documentada durante toda la Edad Moderna, incluso ciertos reparos y transformaciones -se menciona un altar de San Andrés en 1687 en la cabecera de una naveparecen poner de manifiesto un uso creciente, acaso parejo al de la ciudad extramuros ${ }^{52}$.

\section{ORATORIOS MUNICIPALES PARA EL CUMPLIMIENTO DEL PRECEPTO DOMINICAL}

Otras capillas estaban destinadas al cumplimiento del precepto dominical por parte de los fieles que por algún impedimento no podían asistir a las iglesias parroquiales, monásticas y conventuales de la ciudad. Uno de ellos sería el de la Virgen de la Candelaria, situado en alto en la parte exterior de San Dionisio, adonde cada domingo se celebraba una misa para las berceras $^{53}$. Caería en desuso y se arruinaría en la segunda mitad del siglo XVII, sin embargo entre 1712 y 1715 se volvería a edificar, esta vez bajo la advocación de la Divina Pastora, que quedaría como titular del altar hasta su desaparición en $1764^{54}$. Habría otro con idéntico fin en la carnicería ${ }^{55}$. Otro más sería, por razones obvias, el oratorio existente en la cárcel real, en el que don Gonzalo de Mier, visitador general del arzobispado, mandó en 1673 que "cumpliesen en dicho oratorio con el precepto de la Iglesia", esto es, con la obligación que todos los presos tenían, como cualquier otro feligrés, de comulgar por Pascua de Resurrección ${ }^{56}$. Al respecto, no podemos dejar de mencionar el tremendo suceso sacrílego acontecido en el contexto de este precepto pascual un siglo más tarde, concretamente el 13 de abril de 1762, lunes de Pascua, cuando un cura de la colegial acudió a dar la comunión a los presos y uno de ellos, llamado Antonio López, escupió la forma en la cuadra de la cárcel y hasta trató de pisotearla, lo que generó un gran escándalo y la conmoción de toda la ciudad. El mismo día fue expuesto al es-

50 El visitador don Gonzalo de Mier y Barreda, en 1673 describe el templo y las obligaciones del cura: "que cuide del sagrario y de renovar y confesar y baptizar a todos los párvulos quienes sean baptizados en dicha iglesia, así por la mucha gente que hay en esta ciudad, como por que los que fuesen pobres pudiesen ir a cualquiera hora. Y así se continúa y frecuenta esto mucho, porque todas las personas pobres acuden a dicha iglesia". AGAS. Sección II, visitas, legajo 1443, s./f.

51 Tenía Camposanto en 1575, año en el que el hospitalario san Juan Grande compró a don Juan de Villacreces y de la Cueva Alvarado un trozo del mismo para el Hospital de la Candelaria. RíOS MARTínEZ, E. de los, 2003, p. 210.

52 RÍOS MARTÍNEZ, E. de los, 2003, p. 158.

53 AROCA VICENTI, F., 2018, Pp. 118-119.

54 Idem.

55 AGAS. Sección II, visitas, legajo 1443, s./f.

56 Idem. 
carnio público en la argolla y el 25 del mismo mes hubo una solemne función de desagravio en Santo Domingo ${ }^{57}$. A este convento fue llevado López por los inquisidores el 7 de junio, de donde fue sacado al día siguiente, azotándolo por las calles de la ciudad. Finalmente, el 23 de marzo del año 1767, fue ahorcado ${ }^{58}$. Don Juan Dávila Mirabal adquirió el viril donde se guardó la Hostia tras la profanación ${ }^{59}$. No cabe duda de la gran devoción al Santísimo Sacramento de este noble jerezano, dado que años después, cuando levantó su casa de la plaza del Arroyo labró en su portada un relieve relativo a la adoración de la Eucaristía que remata su balcón ${ }^{60}$.

Figura 5

\section{Capilla de San Isidro}

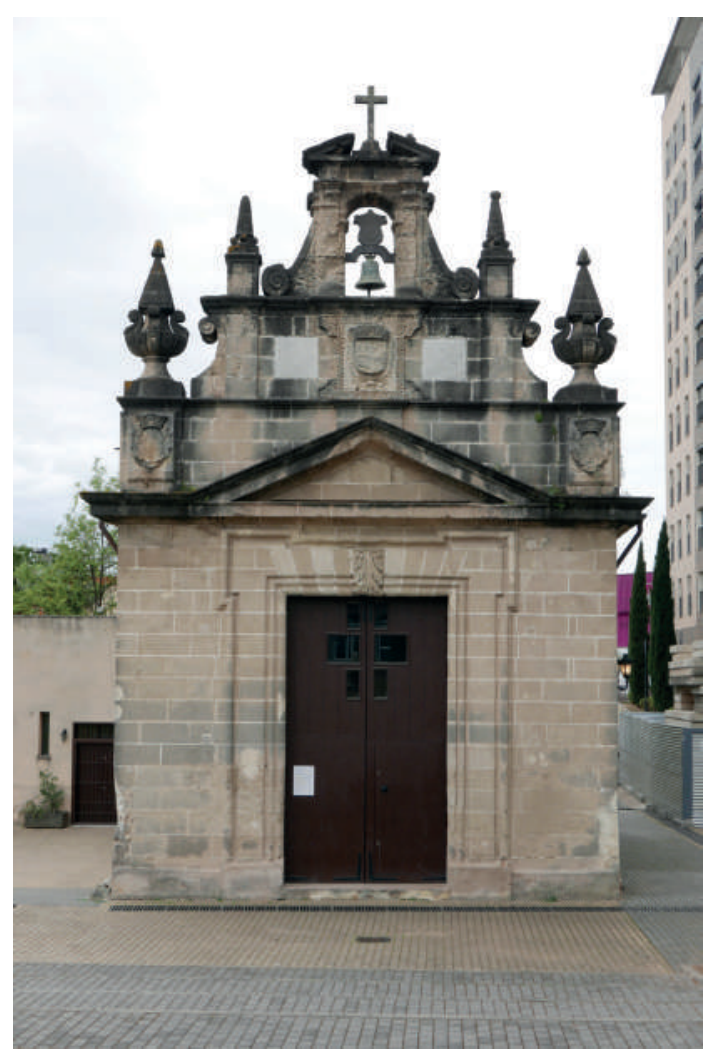

57 TRILLO Y BORBÓN, J. de, 1890. Libro en donde están apuntadas todas las novedades acaecidas en esta ciudad de Xerez de la Frontera desde el año 1753 y algunas otras que han ocurrido fuera de ella. Jerez de la Frontera: Melchor García Ruiz. pp. 7-8. 58 Idem.

59 DOMíngUEZ, J., 1762. Declamación panegyrica-moral en desagravios de Jesu-Christo Sacramentado, por el desacato cometido en la cárcel Real de la M. N. Y L. Ciudad de Xerez de la Frontera, el día 13 del mes de abril del año de 1762, dicha en la sumptuosa fiesta, que, a fin de desagraviar à el mismo Señor ofendido, ideó, è hizo el Real Convento de N.P. S ${ }^{\text {to }}$. Domingo de la referida ciudad, el dia 25 del nombrado mes y año. El Puerto de Santa María: Francisco Vicente Muñoz. passim.

60 ÁLVAREZ LUNA, M. Á. et alii, 2007. La historia de la casa Bertemati. En PINTO PUERTO, F. (coord.). La casa palacio Bertemati (1776-2006). Restauración y rehabilitación para sede del Obispado de Asidonia-Jerez. Jerez de la Frontera: Diócesis de Asidonia-Jerez. p. 51. 
Otra de estas capillas levantadas para el cumplimiento del precepto dominical sería la de San Isidro, en la Alcubilla, en el camino a El Puerto de Santa María (Figura 5). En este caso no serían razones de índole laboral las que impedían a la población que habitaba las inmediaciones acudir a alguno de los templos de la ciudad, sino la relativa distancia a que estos se encontraban y aún más la frecuente intransitabilidad de los caminos que unían esta zona suburbana con la ciudad propiamente dicha. Estas razones fueron las que movieron a la Ciudad a su construcción al tiempo que se reparaba la conducción de agua que provenía de la Cartuja hasta la fuente allí levantada ${ }^{61}$. Así, los veinticuatros jerezanos don Álvaro de Valdespino y don Pedro Yáñez de Cuenca describieron la zona en octubre de 1670 como un "sitio distante de los muros de la çiudad donde ay muchas casas de vezindad muy remota de todas las ygleçias y monasterios de la dicha ciudad, por cuia distancia los vezinos de dicho sitio muchas vezes se quedan sin missa y particularmente en los dias ynvernossos y de aguas" ${ }^{62}$. Por ello informaron al arzobispo que "para consuelo de esta gente determinan mis partes, con acuerdo de la dicha ciudad, fabricar en el dicho sitio una capilla con la advocación del Señor San Ysidro Labrador y adornarla con toda desencia y se celebre en ella el Santo Sacrificio de la Misa y para que esto se consiga para honra y gloria de Dios Nuestro Señor" solicitan las licencias oportunas ${ }^{63}$. El arzobispo solicitó al vicario don Luis de Lara su parecer y éste explicó al prelado "que en el çitio y terreno de la fuente del Alcubilla de treinta años a esta parte se ven los veçinos que tienen la labor de los ladillos y cantareria con grande desconsuelo y desamparo por haberles faltado del dicho çitio la yglesia y convento de los padres de San Agustín de la advocación y título de Nuestra Señora del Socorro y estar como están los dichos vezinos extramuros y distantes de las yglesias para yr a cumplir con el precepto de la misa los días de fiesta y que para que no la aventuren por la distancia y otras raçones de devoción y piedad será mui del servicio de Dios nuestro Señor el conçeder la liçençia que pretende la ciudad, para fabricar una hermita con la advocación de San Isidro Labrador, poniendo en ella un hermitaño o ministro eclesiástico que tenga aprobación del ordinario para que cuide de ella y del serviçio y ornamentos del Altar" ${ }^{\prime 64}$. Finalmente, entre 1674 y 1674, se llevaron a cabo las obras de la ermita bajo la dirección del maestro mayor de la ciudad, Diego Moreno Meléndez, siendo finalmente bendecida el 19 de diciembre

61 ROMERO BEJARANO, M., 2020. El pueblo pereçe de sed. Jerez de la Frontera: Ayuntamiento de Jerez de la Frontera, pp. 163-166.

62 AGAS, Sección II. Serie oratorios, legajo 14 (A), doc. 9, s./f.

63 Idem.

64 Idem. 
de $1675^{65}$. El minúsculo templo, íntegramente de cantería, ostenta es su bóveda, labrado a gran tamaño, el escudo de la ciudad, su promotor y patrono ${ }^{66}$. Pronto debió de venerarse en esta capilla una imagen de la Virgen que, como sucedió con frecuencia en los templos jerezanos durante los siglos XVII y XVIII, terminaría por eclipsar la devoción al santo titular del templo, dado que ya en 1754 el canónigo Francisco de Mesa Ginete la denominaba como ermita de Nuestra Señora de la Alcubilla ${ }^{67}$.

\section{Figura 6}

\section{Oratorio privado del palacio villapanés. Detalle de sus yeserías}

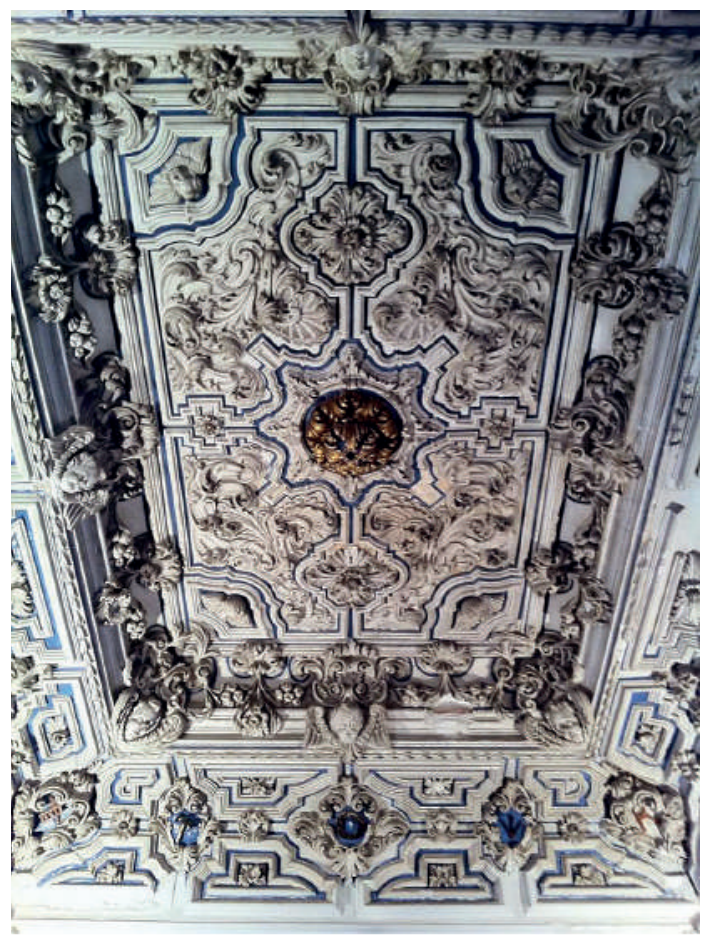

\section{LOS ORATORIOS DOMÉSTICOS}

Además tupir la tela de araña que definía la multitud de edificios de culto que salpicaba la ciudad más allá de cuanto lo lograban los grandes templos parroquiales y conventuales y estas capillas menores, la sacralización del medio vital civil alcanzaba su ápice al penetrar

65 AROCA VICENTI, F., 2018, P. 121.

66 MARISCAL RODRÍGUEZ, M. Á. y POMAR RODIL, P. J., 2004. p. 148.

67 MESA GINETE, F. de, 1888. t. II, p. 285. Sobre el desplazamiento de los titulares de los templos por la creciente devoción a la Virgen durante los siglos XVII y XVIII, véase POMAR RODIL, P. J., 2019. El fervor mariano y la versatilidad del retablo. Algunos ejemplos parroquiales de Jerez de la Frontera. En Trocadero, nº 31, pp. 83-101. 
en el propio caserío, especialmente en los palacios y casas principales, que ostentaban oratorios domésticos de naturaleza privada. Estas capillas se erigían en las casas particulares para comodidad de una persona o una familia, no podían consagrarse ni ser bendecidos a modo de iglesias, sino sólo con la bendición loci vel domus novae del Rituale Romanum, llevando aparejados en su uso una serie de restricciones ${ }^{68}$. La documentación que más información nos aporta sobre las capillas domésticas de la antigua vicaría de Jerez de la Frontera es la referente a las peticiones de licencia sacramental ${ }^{69}$. Estos títulos, que debían ser expedidos por el Arzobispado, habilitaban para que, por motivos razonables, pudieran celebrarse en los oratorios tanto el sacrificio de la misa como otros actos de culto. Pese a su naturaleza privada, quedaban desde luego sujetos a la visita pastoral, instrumento de control y gobierno eclesiástico que tras el Concilio de Trento adquirió singular sistematización y desarrollo y que, como hemos ya visto en este trabajo, supone con frecuencia un rico caudal de noticias de índole cultual e histórico artística.

La motivación venía dada por la comodidad de cumplir el precepto dominical sin salir de casa, principalmente en época de lluvias, sin desdeñar el prestigio social ligado al privilegio de oratorio, dada la necesidad de probar nobleza o hidalguía para que se les concediese. Finalmente, conviene señalar que la licencia se expedía para una persona en concreto, su cónyuge y eventualmente los miembros de su familia, y siempre que una causa razonable, como la vejez o la enfermedad, así lo justificase ${ }^{70}$. Repasar a través de las licencias y de las visitas pastorales los nombres de las familias beneficiadas con el privilegio de oratorio es repasar la historia nobiliaria de la ciudad: Mirabal, Espínola, López de Carrizosa, Fuentes, Pavón, Romano de Mendoza, Cabeza de Vaca, De la Cerda, Ponce de León, Melgarejo, Villavicencio, Dávila, Suárez de Toledo... En el caso de este último linaje, podemos comprobar cómo el oratorio privado de don Dionisio tuvo un ulterior desarrollo público, como Capilla de Nuestra Señora de Belén. Así nos lo describe el visitador don Gonzalo de Mier en 1673: “en

68 BRAUN, J., 1927. Diccionario manual de liturgia. Madrid: Editorial Voluntad. ad vocem.

69 Entre 1567 y 1789 hemos localizado 168 peticiones de licencia para oratorios de Jerez de la Frontera, de los cuales 139 son urbanos y 29 rurales. AGAS, sección II, serie 9, legajos 14-A y 14-B.

70 La mención delos posibles asistentes en las bulas viene determinada por el carácter estricto delas ya mencionadas Constituciones Sinodales que prescribían que "Y porque son muchos los que tienen licencia para decir u oír Misa en oratorios particulares, los cuales usan della con poca devoción y decencia. S. S. A. Estatuimos y mandamos que ningún Clérigo, secular ni regular, diga Misa en oratorio particular, en esta Ciudad ni en ningún lugar de nuestro Arzobispado, aunque está visitado y aprobado por Nos ó por alguno de nuestros Predecesores, si no fuese estando alguna de las personas a cuya instancia se aprobó el dicho oratorio, o su mujer o alguno de sus hijos". Constituciones del Arzobispado de Sevilla hechas y ordenadas por el Ilustrísimo $\gamma$ Reverendísimo Sr. D. Fernando Niño de Guevara, Cardenal $\gamma$ Arzobispo de la Santa Iglesia de Sevilla, en el Sínodo que celebró en su Catedral año de 1604; $\gamma$ mandadas imprimir por el Dean y Cabildo, Canónigos in Sacris, Sede vacante, en Sevilla, año de 1609. 1862 y 1964. Sevilla: Francisco Álvarez y Ca. t. II, pp. 32-33. 
forma de Capilla que sale a la calle y se dice misa los días de fiesta y el demás tiempo está cerrado". Se hizo con licencia del arzobispo Pimentel "por causa que estando en el mismo sitio esta imagen embutida en la pared por devoción del dueño de la casa unos moros la apedrearon y así se dio licencia y se hizo procesión por la ciudad y se hizo la capilla donde está colocada en desagravio de tan grande desacato año de 1650 y tiene despachos y licencia en toda forma y un jubileo el primer domingo de agosto con bulas de su santidad"71 . Muchas de las casas que debieron acoger los oratorios mencionados se perdieron, transformaron y poca memoria queda de la mayor parte de los mismos. Al respecto, el techo de yeserías del oratorio de la casa del Marqués de Villapanés en la Cruz Vieja (Figura 6), la cúpula y retablo de la casa del canónigo Menchaca, y el de armario del palacio de los villacreces, ambos en la plaza de Rafael Rivero, o el altar del oratorio del desaparecido palacio del marqués de los Álamos del Guadalete, conservado en la parroquia de San Marcos son algunos de los pocos testimonios que perviven.

\section{LOS ORATORIOS RURALES}

Curiosamente, algunas de las capillas rurales del extenso término jerezano se encontraban bajo la jurisdicción eclesiástica de la diócesis de Cádiz, dado que la de Sevilla llegaba sólo hasta la ribera norte del río Guadalete. Es por ello que ermitas como la sumergida de El Mimbral o la histórica de La Ina, ambas tan íntimamente ligadas a la historia de Jerez, no formasen parte de su vicaría, al igual que les sucedía a las hoy desaparecidas de Santiago y San Cristóbal, en tierras siempre en litigio entre Jerez y El Puerto ${ }^{72}$. Otras ermitas del alfoz jerezano fueron el origen de conventos, monasterios y hasta parroquias, como fueron los casos de Nuestra Señora de Guía, donde se asentaron inicialmente los agustinos; El Sotillo, germen de la futura Cartuja; o las ya mencionadas de San Miguel y Santiago que devinieron en las parroquias homónimas. De alguna más queda vaga memoria como podría ser el caso de la del Portal de Belén ${ }^{73}$, que acaso pueda estar relacionada con la barriada rural de El Portal, para la que se ha apuntado un origen medieval ${ }^{74}$. La funcionalidad de estas

\footnotetext{
71 AGAS. Sección II, visitas, legajo 1443.

72 Sobre el origen medieval de estas ermitas de Santiago y San Cristóbal, véase JIMÉNEZ LÓPEZ DE EGUILETA, J. E. 2016-2017. Expresiones de la religiosidad medieval en la región gaditana (siglos XIII-XIV). Alcanate, n⿳0. 10, pp. 159-160.

73 Don José de Almoriña, visitador general del Arzobispado de Sevilla, menciona en 1740 la existencia de varias ermitas y añade que se había levantado "ultimamente la que dizen del Portal de Belem a media legua de distante desta ciudad". AGAS. Sección II. Serie visitas, legajo 1385, s./f.

74 GRANDALLANA Y ZAPATA, L. de, 1885. Noticia histórico-artística de algunos de los principales monumentos de Jerez. Jerez de la Frontera: Gautier Editor, p. 27; JIMÉNEZ LÓPEZ DE EGUILETA, J. E. 2016-2017, p. 159.
} 
ermitas, más allá de su carácter conmemorativo o votivo hay que ponerla en relación con la crecida población que vivía en el campo y con la que a éste se movía a diario desde la ciudad. Agustín de Horozco, a finales del XVI, al describir la ciudad de Jerez, señaló que "habita en ella grande número de gente que acude al trabajo y labor de las fertilísimas heredades, cortijos y crías de ganados de su extendida campiña y término" ${ }^{75}$. Por ello encontramos alusiones a la necesidad de adelantar el horario de las misas matutinas dentro de la ciudad, como es el caso formulado por el oratorio del Hospital de la Caridad de Jerez ${ }^{76}$, para posibilitar la asistencia a ellas de estos trabajadores que salían al campo cada mañana, lo que, amén de ser un exponente manifiesto de la estrecha e indisoluble relación campo-ciudad que perduró durante toda la Edad Moderna, y aun posteriormente, en una agrociudad como Jerez, nos da la medida de la utilidad de estas capillas rurales ${ }^{77}$.

Estarían también los oratorios rurales fundados en tierras de particulares, que podrían tener un uso privado o público ${ }^{78}$. La motivación de los primeros, pequeñas capillas domésticas ubicadas en el señorío de la casa de campo, sería casi idéntica a la que movía a la construcción de los de naturaleza urbana, si bien en este caso más justificada aún dada en la distancia existente entre finca y ciudad. Convergía con la razón nobiliaria en los segundos una cierta conciencia pastoral que moralmente obligada a los propietarios de las tierras a proporcionar a quienes se las labraban los medios espirituales suficientes para su salvación, como se pone de manifiesto en las licencias solicitadas al ordinario. El número de las que hemos localizado de los siglos XVII y XVIII, trece y quince respectivamente, parece indicar una continuidad sin notables incrementos ni bajadas en el marco cronológico de esos doscientos años. Estos documentos ponen de manifiesto además que casi la totalidad de las casas de campo con oratorio, frecuentemente ligadas al cultivo de la vid, no estaban lejanas de la ciudad ${ }^{79}$. Cuando, por las ya apuntadas razones de índole pastoral, se deseaba

75 HOROZCO, A. de, 2001 [ms. 1598]. Historia de la Ciudad de Cádiz. Cádiz: Universidad de Cádiz. p. 163.

76 AGAS. Secc. II, serie 9, legajo 14 (A), exp. 26.

77 Sobre la ocupación mayoritariamente agrícola de la población de Jerez véase MARCOS MARTíN, A., VELA SANTAMARÍA, F. J., 1978. Las grandes ciudades campesinas de Andalucía Occidental en el siglo XVI. El caso de Jerez de la frontera. En Actas del I Congreso de Historia de Andalucía. Córdoba: Monte de Piedad y Caja de Ahorros de Córdoba. t. II, Pp. 403-417.

78 En el tratado de Giovanni Battista Gattico, concretamente en el capítulo tercero De differentia Inter. Oratorium Publicum, et Privatum pueden confrontarse las diferencias que entre ambos tipos de oratorios - públicos y privadosse reflejarán en el texto. GATTICO, J. B., 1746. De Oratoriis domesticis et de usu altaris portatilis juxtà veterem ac recentem Ecclesice Disciplinam Ecclesiasticorum Seculariumque Virorum Singula Jura \& Privilegia complectentem. Roma: Typographia Generosi Salomoni. pp. 9-19.

79 AGAS. Sección II, visitas, legajo 1443, s./f.; POMAR RODIL, P. J., 2002. Los oratorios rurales de la vicaría jerezana durante los siglos XVII y XVIII. En: POMAR RODIL, P. J. (Ed.) Haciendas $\gamma$ Cortijos. Historia $\gamma$ Arquitectura en Andalucía $\gamma$ América. Sevilla: Universidad de Sevilla, p. 178. 
que el oratorio rural tuviese carácter público, los propietarios de las fincas emprendían la construcción de pequeñas capillas rurales donde los trabajadores -y también los señores durante la temporada de residencia- podían cumplir siempre, a excepción de los días de Navidad, Pascua y Pentecostés, que estaban obligados a asistir a sus parroquias, con el precepto de oír misa los domingos y días de fiesta ${ }^{80}$. En ocasiones, la construcción de uno de estos oratorios no sólo beneficiaba a los labriegos del mismo, sino también a los de los circunvecinos, como se señala en la petición de licencia para los oratorios de don Lorenzo Fernández de Villavicencio en sus cortijos de Vallehermoso y Pozuela ${ }^{81}$. Uno de los testimonios más ricos en este sentido es el que nos proporciona la licencia solicitada en 1675 por el capitán gaditano Simón de Fonseca para el oratorio de su finca de Parpalana. En la solicitud, uno de los testigos informa de que "la dicha heredad de Parpalana está muy distante desta ciudad y que mediante el estarlo si el tiempo es de llubias no pueden venir los labradores y demás personas que asisten en el territorio los días festivos de precepto no pueden ir a la iglesia pública a oír misa porque se ponen los caminos de suerte con los temporales que es imposible el poderlos caminar si no es con mucho trabajo" ${ }^{\prime 2}$.

Pero estas capillas u oratorios a los que concurrían los habitantes y trabajadores del campo, sí que tenían una serie de requisitos privativos a su naturaleza que debían cumplir debidamente para poderse en ellos celebrar el sacrificio de la misa: ser pieza arquitectónicamente separada del señorío, instalaciones agropecuarias y viviendas de los labriegos y servidores, disponer de campana con la que convocar a los servicios religiosos y contar con puerta abierta al campo o camino público ${ }^{83}$. Estos dos últimos requisitos fueron los que, al redundar en espadaña y portada, imprimieron a estas capillas su inconfundible apariencia que las identifica como edificio eclesiástico, constituyendo ambos los elementos que quizá mejor traduzcan el fenómeno de la aprehensión de la arquitectura culta urbana por parte de la popular rural, proporcionando además al edificio su animado y pintoresco volumen y que, junto con la torre del molino, si la hubiere, suponen los dos únicos hitos de verticalidad en la monocorde horizontalidad de las haciendas, cortijos y casas de viña del entorno jerezano.

80 Así lo encontramos repetidamente tanto en las licencias como en las Constituciones Sinodales que señalaban "que no se diga en ellos [en los oratorios] más de una Misa cada día. Que no se diga los primeros días de Pascua, porque no falten en días tan solemnes de sus parroquias. Rosalía Vinuesa por su parte ha señalado que tampoco se permitía la celebración en los días de la Asunción, Epifanía, Anunciación a la Virgen, santos Pedro y Pablo, Todos los Santos y el patrón de la ciudad". Constituciones del Arzobispado... t. II, PP. 32-33; VINUESA HERRERA, R., 1996, Oratorios en la Vicaría de Estepa: Expedientes y descripción. En: Actas de las II Jornadas sobre Historia de Estepa. El Marquesado de Estepa. Estepa: Ayuntamiento de Estepa. p. 528.

81 AGAS. Secc. II, serie 9, legajo 14 (A), exp. 40.

82 AGAS. Secc. II, serie 9, legajo 14 (B), exp. 116.

83 POMAR RODIL, P. J., 2002. p. 173. 
El uso compartido entre nobles y campesinos llevará a los primeros a buscar la ubicación que más adecuadamente señale su status dentro del oratorio y a tal fin, en ocasiones, abrieron una suerte de ventana o tribuna desde sus habitaciones, para poder desde ellas presenciar los oficios de manera más cómoda y evitando así mezclarse con los trabajadores de la tierra. Para contar con esta ventana o tribuna abierta desde el señorío al oratorio era necesaria una bula especial, ya que las Constituciones Sinodales eran claras al respecto, prohibiendo estos balcones privilegiados debido a los inconvenientes que acarreaba su uso por la falta de decoro con que los señores asistían a misa desde sus casas ${ }^{84}$. Aunque en el amplio límite del arzobispado hispalense encontramos bastantes casos de oratorios rurales que contaron con un espacio de esta índole, algunos todavía conservados, en la vicaría de Jerez tan sólo hemos dado con una alusión al respecto en La Granja de San Andrés, del comerciante gaditano José de Miranda ${ }^{85}$. Aún así, de la lectura de la documentación se desprende que no se llegó a abrir finalmente la ventana enrejada para la que le habilitaba la bula obtenida.

\footnotetext{
84 "En muchas iglesias de esta Ciudad y nuestro Arzobispado, hay ventanas y miradores, de á donde los dueños de las casas que están junto a ellas, oyen los divinos Oficios desnudos y sin acabarse de vestir, cosa muy indecente y escandalosa. Para remedio de lo cual (en ejecución del Proprio motu del Papa Pío V, de felice recordación) Sancta Synodo Approbante mandamos que ninguna persona, de ningún estado y condición que sea, tenga abierta ventana ó mirador de su casa a la iglesia; y si algunas hubiere, las cierren y hagan cerrar". También para el caso específico de los oratorios se preocuparan por estos extremos las sinodales, al prohibir la celebración de la misa "si los susodichos y las demás personas que se hallaren presentes, no estuvieren con hábito decente: conviene a saber; las mujeres con mantos, y los hombres con capas y no con ropas de levantar". Constituciones del Arzobispado..., t. II, pp. 14-15 y 32-33.

85 POMAR RODIL, P. J., 2002. pP. 175-177.
} 